\title{
Rationalisation in public dental care - impact on clinical work tasks and mechanical exposure for dentists - a prospective study
}

\author{
Jonker, D.; Rolander, B.; Balogh, I.; Sandsjö, L.; Ekberg, K.; Winkel, Jørgen
}

\section{Published in: \\ Ergonomics}

Link to article, DOI:

10.1080/00140139.2012.760751

Publication date:

2013

Link back to DTU Orbit

Citation (APA):

Jonker, D., Rolander, B., Balogh, I., Sandsjö, L., Ekberg, K., \& Winkel, J. (2013). Rationalisation in public dental care - impact on clinical work tasks and mechanical exposure for dentists - a prospective study. Ergonomics, 56(2), 303-313. https://doi.org/10.1080/00140139.2012.760751

\section{General rights}

Copyright and moral rights for the publications made accessible in the public portal are retained by the authors and/or other copyright owners and it is a condition of accessing publications that users recognise and abide by the legal requirements associated with these rights.

- Users may download and print one copy of any publication from the public portal for the purpose of private study or research.

- You may not further distribute the material or use it for any profit-making activity or commercial gain

- You may freely distribute the URL identifying the publication in the public portal 


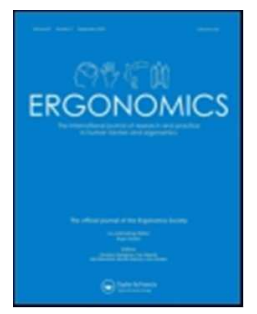

\section{Rationalisation in public dental care - impact on clinical work tasks and mechanical exposure for dentists - a prospective study}

\begin{tabular}{|r|l|}
\hline Journal: & Ergonomics \\
\hline Manuscript ID: & TERG-2011-0332.R2 \\
\hline Manuscript Type: & Original Article \\
\hline Date Submitted by the Author: & 22-Nov-2012 \\
\hline Complete List of Authors: & $\begin{array}{r}\text { Jonker, Dirk; National Centre for Work and Rehabilitation., Department of } \\
\text { Medical Health Sciences, Linköping University } \\
\text { Rolander, Bo; National Centre for Work and Rehabilitation, Department of } \\
\text { Medical Health Sciences, } \\
\text { Balogh, Istvan; Laboratory Medicine, Occupational and Environmental } \\
\text { Medicine } \\
\text { Sandsjö, Leif; MedTech West/School of Engineering, University of Borås, } \\
\text { Borăs, } \\
\text { Ekberg, Kerstin; National Centre for Work and Rehabilitation, Department } \\
\text { of Medical Health Sciences } \\
\text { Winkel, Jörgen; Univesity of Gothenburg, Department of Work Science }\end{array}$ \\
\hline Keywords: & $\begin{array}{l}\text { task analysis < Human-Machine Systems, work organisation < } \\
\text { Organisational Ergonomics, risk assessment and management < Health } \\
\text { and Safety, musculoskeletal disorders < Health and Safety, health care } \\
\text { ergonomics < Application Domains }\end{array}$ \\
\hline
\end{tabular}




\section{Rationalisation in public dental care - impact on clinical work tasks and mechanical exposure for dentists - a prospective study}

\footnotetext{
${ }^{1}$ National Centre for Work and Rehabilitation, Department of Medical Health Sciences, Linköping University, Sweden.

${ }^{2}$ Futurum - Academy for health and care, Jönköping, Sweden.

${ }^{3}$ Department of Occupational and Environmental Medicine, Lund University, Sweden ${ }^{4}$ MedTech West/School of Engineering, University of Borås, Borås, Sweden

${ }^{5}$ Department of Sociology and Work Science, University of Gothenburg, Sweden

${ }^{6}$ Department of Management Engineering, Technical University of Denmark, Denmark
}

Corresponding author:

Dirk Jonker, BScPT, PhD.

Occupational Safety and Health Centre

County hospital Ryhov, Jönköping, Sweden

E-mail: dirk.jonker@,lj.se

Tel +46 36322835 


\begin{abstract}
Swedish dentistry has been exposed to frequent rationalisation initiatives during the last half century. Previous research has shown that rationalisation often results in increased risk of developing work-related musculoskeletal disorders, thus reducing sustainability in the production system.

In the present prospective study we assessed mechanical exposures among Swedish dentists in relation to specific rationalisations of clinical dental work during a six-year period. Body postures and movements of 12 dentists were assessed by inclinometry synchronised to video recordings of their work.

No rationalisation effects could be shown in terms of a reduction in non-Value-Adding Work ('waste'); and at job level no major differences in mechanical exposure could be shown between baseline and follow-up.

Conclusion: the present rationalisation measures in dentistry do not seem to result in rationalisation at job level, but may potentially be more successful at the overall dental system level.
\end{abstract}

Keywords: Loss analysis; Sustainable production system; Inclinometry; Video analysis

\title{
Statement of relevance
}

In contrast to many previous investigations of the mechanical exposure implications of rationalisation, the present rationalisation measures did not increase the level of risk for dentists. It is highlighted that all occupations involved in the production system should be investigated in order to assess production system sustainability. 


\section{Introduction}

Work-related Musculo-Skeletal Disorders (WMSD) are a main occupational health issue for dentists in modern dentistry (Finsen et al. 1998, Akesson et al. 1999). The complaints are mainly localised to the shoulder/neck and back regions (Ratzon et al. 2000, Leggat et al. 2007, Hayes et al. 2009).

In a recent review by Westgaard and Winkel (2011) it is concluded that “... the potential of rationalisations to cause health problems is large, contrasting the overall assessment of ergonomic interventions that seem to have limited health effects in a long range perspective". The authors therefore emphasise that there is a need to understand the health effects of rationalisation to ensure "sustainable production systems", which they define as "the joint consideration of competitive performance and working conditions in a long term perspective". The term "rationalisation" was defined at the World Economic Conference in Geneva in 1927 as " ... the methods of technique and of organisation designed to secure the minimum waste of either effort or material. ...".

Accordingly, it has been suggested that WMSD among dentists in Sweden are partly related to the rationalisation of dentistry, starting in the 1960s based on Tayloristic principles (Bjorkman 1996, Winkel and Westgaard 1996). Different rationalisation principles have dominated over time (e.g. Bejerot et al. 1999, Westgaard and Winkel 2011), but all include the general aim of improving performance by reducing duration of tasks considered as waste.

In a recent study, we showed reduced mechanical risk factors for WMSD during tasks characterised as "waste", compared with so-called "Value-Adding Work (VAW) (Jonker et al. 2011). VAW is here defined as the portion of process time the worker spends on actions that create value as perceived by the customer (Keyte and Locher 2004). This suggests that further rationalisation where VAW activities are increased may also lead to an increase in 
mechanical risk factors for developing WMSD among dentists. However, mechanical risk factors may also arise during tasks typically considered as non-VAW for dentists, such as administrative work tasks (Tornqvist et al. 2009).

A Swedish government report presented in 2002 recommended that the Public Dental Service should be reorganised to obtain a more efficient mix of tasks between the occupational groups (SOU 2002:53). Through task reallocation, dental hygienists and dental nurses should now perform some of the work performed by dentists.

Due to these recommendations, which stemmed from a problematic financial situation, but are also brought about by recent developments in information technology, the public dental care system of Jönköping County Council decided to implement a number of organisational and technical rationalisations starting in autumn 2003 (Munvädret 2003:9).

In the present study, we evaluate changes at both the organisational and the technical level made between 2003 and 2009. The following changes were implemented in work organisation: some of the dentist's tasks were delegated to lower-level professions with appropriate education; small clinics were merged with larger ones in the same region; financial feedback was given to each clinic on a monthly basis; dentists' salaries were increased from below the national average to slightly above; an extra management level was implemented between top management and the directors of the clinics.

The technical changes comprised introduction of: a SMS reminder system to patients, with the aim of preventing loss of patients' visits to the clinics; digital X-ray at the clinics; a new IT system to enable online communication between healthcare providers and insurance funds; a self-registration system for patients on arrival for both receptionist and dental teams.

The aim of the present study was to investigate the impact of the above-mentioned rationalisations in dentistry at both job and task level, of dentists regarding changes in i) duration of "waste", and ii) mechanical exposures in the neck, shoulder, and back. 


\section{Material and methods}

\subsubsection{Methods}

The study is a prospective cohort study. In 2003 the public dental care system of Jönköping County Council decided to implement a number of organisational and technical rationalisations (Munvädret 2003:9). These were then implemented during the following five years. Data were collected in 2003 and 2009 at dentists' normal workplaces, with the same type of regular work being conducted on both occasions. Four hours of direct technical measurements of mechanical exposure were recorded, starting with the first patient in the morning and ending at lunchtime. During the first 45 minutes of the measurement period, video recordings were also made, synchronised to the direct technical measurements. Work tasks were assessed from the video recordings and corresponding task-specific exposures obtained, as described below.

\subsubsection{Classification of work tasks and assessment of their duration}

The work performed by the dentists was videotaped during the first 45 minutes for each investigated dentist, using a digital camera (Canon MVX30i). The work tasks were classified according to Table 1 with the assistance of an experienced dentist. The duration of these work tasks was then assessed from the video recordings with a sampling frequency of $1 \mathrm{~Hz}$, by using a video analysis system ("Videolys" system: Chalmers University of Technology, Engström and Medbo 1997) and further classified into VAW and non-VAW (Table 1). One experienced researcher analysed the video recordings according to Kazmierczak et al (2006).

In the present study, VAW was operationalised according to Neumann et al (2006). This is an engineering approach used in assembly work and includes any assembly work and acquisition of components or tools that can be completed without the operators having to move from their assembly position. According to this approach, all intra-oral patient work and 
all treatment-related dialogue with the patient without leaving the working position were considered as VAW.

Periods of disturbances caused by the researchers were identified and excluded from further analyses. The video recording was stopped during scheduled breaks. Baseline data were obtained from Jonker et al. (2011). In that study, the job as a dentist was classified into six work tasks. "Patient treatment" and "Dental information" were classified as VAW, and the remaining four tasks, i.e. "X-ray handling", "administration", "handling of parts and materials", and "disturbances”, were classified as non-VAW (i.e. "waste”).

\subsubsection{Mechanical exposure}

Inclinometers based on triaxial accelerometers were used to record the flexion/extension of the head, trunk and upper arm elevation relative to the line of gravity. Data were sampled at $20 \mathrm{~Hz}$ using a datalogger (the inclinometers and datalogger were manufactured by Logger Teknologi HB, Åkarp, Sweden) (Hansson et al. 2001). The analogue signals from the accelerometers were anti-alias filtered, using a Butterworth filter with a $3 \mathrm{~dB}$ point at $10 \mathrm{~Hz}$ and a slope of $24 \mathrm{~dB}$ per octave. A 12-bit analogue-to-digital converter was used, with a span corresponding to roughly $4 \mathrm{~g}$; i.e., the resolution was approximately $0.002 \mathrm{~g}$ per least significant bit (AD unit). The first step in the data processing was the filtering of the sampled accelerometer data using a low-pass, finite-duration impulse response filter with a cut-off frequency of $5.0 \mathrm{~Hz}$.

Postures and angular velocities were calculated for each activity category obtained, by synchronising the video and inclinometer recordings (Forsman et al. 2002).

One inclinometer was placed on the forehead, another on the upper back to the right of the cervical-thoracic spine at the level of $\mathrm{C} 7$ and Th1. For the upper arms, the inclinometers were fixed to plastic plates $(55 \times 27 \mathrm{~mm})$ that were placed along the upper arm, with the lateral 
edge along the line from the lateral posterior corner of the acromion to the lateral epicondyle, and with the upper edge at the insertion of the deltoid muscle (Hansson et al. 2006).

All recordings started with a calibration procedure where a reference position was established and recorded for the head, upper back and upper arms respectively for 5 seconds. The reference position for the head and upper back (zero degrees flexion) was defined as the position obtained when the subject was standing, looking at a mark at eye level. The forward direction of the head and back was defined with the subject sitting, leaning straight forward, looking at the floor (Hansson et al. 2006). For the reference position of the upper arms, an elevation of zero degrees was recorded with the side of the body leaning against the backrest of a chair, the arm hanging perpendicular over the backrest of the chair with a dumbbell of $2 \mathrm{~kg}$ in the hand.

\subsubsection{Job and task exposures}

"Job exposures" were estimated based on the four hours of inclinometry recordings. For comparison, job exposure was also estimated for the 45 minutes when video recordings were performed. "Task exposures", i.e. the exposures obtained for the six different tasks were based on the 45 minutes of recording when the dentists were video-filmed. Specific "task exposures" were calculated for the tasks indicated in Table 1 according to the periods assessed by the Videolys and the corresponding inclinometer recordings. By assessing task exposures, we calculated the exposures during VAW and non-VAW. 


\subsection{Subjects}

In 2003, 16 dentists participated in the study (Jonker et al. 2011). Twelve of these 16 dentists were still available in 2009. In 2003, these 12 dentists (5 male and 7 female) had a mean age of $51(\mathrm{sd}=6.4$, range: $39-59)$ years and had worked as dentists for an average of 22 ( $\mathrm{sd}=7.4$, range: 9-37) years. All were right-handed and employed in dental clinics in Jönköping County, Sweden.

\subsection{Data analysis}

Descriptive statistics are presented as means (m), and 95 percent confidence intervals (CI $95 \%$ ). For the inclinometry data, we used group means of the $50^{\text {th }}$ percentile, group means of differences between the $90^{\text {th }}$ and $10^{\text {th }}$ percentiles, and 95 percent confidence interval (CI 95\%). Paired t-tests were used in order to analyse changes between year 2003 and 2009 for postures and movement velocities during the same kind of work tasks, job exposure during both 45 minutes and four hours, and time distribution of observed time for VAW and non-VAW during clinical dental work. Paired t-tests were also used in order to detect differences in job exposures based on 45 minutes and four hours of recordings, in 2003 as well as 2009.

The Kolmogorov-Smirnov test of normality showed that the time distributions for VAW and non-VAW activities were significantly separated from normality $(p<0.05)$. Those variables were tested with the Wilcoxon signed-rank test for related samples.

Differences in postures, movement velocities and time consumption of $10 \%$, are assumed to be of clinical relevance. With a statistical power of $80 \%$ and a calculated $\mathrm{CV}$ of 0.28 and 0.24 for measured workload and VAW time consumption respectively, a sample size of 10 persons is required (Balogh et al.1999).

Significance was assumed at $\alpha=0.05$ level. All statistical calculations have been performed using SPSS (Chicago, Illinois 60606 version 16.0). 


\section{Results}

\subsection{Changes in time distribution of work tasks}

The average duration of non-VAW in relation to the total recording time tended to increase from $43 \%$ at baseline in 2003 to $55 \%$ in $2009(\mathrm{p}=0.10)$. The average duration of "patient treatment" (part of VAW) tended to decrease from $47 \%$ in 2003 to $34 \%$ in 2009 ( $p=0.14$ ), and "handling of parts and materials" (part of non-VAW) tended to increase from $14 \%$ to $18 \%$ of the recording time $(p=0.10)$ (Table 1$)$.

\section{[Table 1]}

\subsection{Performance during the video recordings}

The performance in terms of average number of patients treated during the video recordings was 2.25 in both 2003 and 2009. The average duration of uninterrupted periods of non-VAW, which can be seen as a measure of porosity of the work, tended to increase by 41 seconds, from 65 seconds in 2003 to 106 seconds in $2009(\mathrm{p}=0.09)$ (Table 2).

[Table 2]

\subsection{Mechanical exposure during VAW tasks}

The median head inclination during "patient treatment" increased from $40^{\circ}$ in 2003 to $46^{\circ}$ in $2009(p=0.007)$. The range of postures and movement velocities $(90$ th -10 th percentiles $)$ for the head were reduced by $10^{\circ}$ and $5^{\circ} / \mathrm{s}$ respectively at follow-up. The range in movement velocities (90th - 10th percentiles) for the right upper arm was also significantly decreased in 2009 , by $11^{\circ} / \mathrm{s}$ (Tables 3 and 4$)$.

In general, during "dental information" no changes in mechanical exposure values, either for postures or movement velocities, were found at follow-up. 


\subsection{Mechanical exposure during non-VAW tasks}

During "X-ray handling", the median elevation of the left upper arm was reduced from $35^{\circ}$ in 2003 to $23^{\circ}$ in 2009 ; the range of both right and left upper arm postures (90th - 10th percentiles) was reduced by $10^{\circ}(0.005<\mathrm{p}<0.04)$ (Table 3$)$. A tendency towards a $6^{\circ} / \mathrm{s}$ reduction in median movement velocities was found at follow-up for the dominant upper arm $(p=0.08)$, and the movement velocity range (90th -10 th percentiles) was reduced by $15^{\circ} / \mathrm{s}$ $(p=0.01)$ (Table 4).

During "administration", the median movement velocities and the range of movement velocities were in general reduced for all the studied body segments in 2009 compared with 2003. Also, a tendency to a narrower posture range (90th -10 th percentiles) was found for back and upper extremities in 2009 compared with 2003.

"Handling of parts and materials" demanded increased median movement velocities for the head $\left(2.9^{\circ} / \mathrm{s}, \mathrm{p}=0.02\right)$ and the left upper $\operatorname{arm}\left(9^{\circ} / \mathrm{s}, \mathrm{p}=0.03\right)$ in 2009 compared with 2003 . In 2009 , the velocity ranges (90th - 10th percentiles) for both upper arms and back movements were significantly increased, compared with $2003\left(23-29^{\circ}, 0.02<\mathrm{p}<0.05\right)$ (Tables 3 and 4$)$.

\subsection{Mechanical exposure during pooled VAW compared with pooled non-VAW}

No major exposure changes were found, except for a $4^{\circ}$ increase in head inclination during VAW, from 2003 to 2009.

In both 2003 and 2009, VAW compared with non-VAW implied more forward-flexed postures for the head and back, and lower median movement velocities and movement velocity ranges (90th - 10th percentiles) of the head, back and upper arm (Tables 3 and 4). 


\subsection{Job exposure}

Estimation of job exposures showed no major differences between baseline and follow-up, neither based on evaluation of the 45 minutes synchronised to the video recordings nor on the full four hours of recording from the first patient in the morning through to lunch. Details are given in Tables 3 and 4.

[Table 3] and [Table 4] 


\section{Discussion}

In spite of several rationalisation initiatives during the investigated period (2003 to 2009) the duration of non-VAW (waste) at follow-up in 2009 was not reduced, but rather showed a trend towards an increase. Accordingly, no major changes in mechanical exposure at job level could be shown. At task level, however, mechanical exposure during VAW became more constrained, while one in four of the non-VAW tasks became more varied.

\subsection{Methodological considerations}

\subsubsection{Exposure assessments}

In the present study, detailed information on mechanical exposure has been evaluated by combining direct posture and movement measurements with video-based observations of work-task distribution according to previously described procedures (Jonker et al. 2011). This allows us to study aspects of exposures rarely considered in epidemiology and intervention studies. Furthermore, it allows studies of the potential effects of rationalisation when reducing the amount of waste/non-VAW. However, our assessments were confined to dentists, while the performed rationalisations aimed to reduce waste at system level. Thus, the lack of waste reduction among the dentists may not be valid at system level.

The method used for measurement of mechanical exposure has shown good precision and high reliability (Hansson et al. 2006). In addition, the data were obtained during normal work and at the regular workplace to improve validity.

The representativity of 45 minutes of video recordings may be questioned. Mathiassen and Svendsen (2009) showed, when studying right upper arm movements among house painters, that sample duration longer than 40 minutes is needed to reduce mechanical exposure bias in $10^{\text {th }}$ and $90^{\text {th }}$ percentiles to below $25 \%$ of true whole-day exposure. However, the investigated exposure ranges among dentists are presumed to be smaller compared with the range of movements among housepainters. This suggests a small overall mechanical job exposure bias 
in the present study. In line with this, we found only minor differences between job exposure data obtained from 45 minutes and four hours of recording. However, a larger inter-day variation in exposures may still occur.

Only working postures and movements of the neck and upper extremities were measured with the inclinometer in the present study. Dong et al. (2007) have shown a significant interaction between differently designed dental tools and measured physical workload in the lower arms during simulated dental work. In a more recent study of dental hygienists, high muscular load in the trapezius and forearm extensors was found during manual scaling (Akesson et al. 2012). The effect of such forces during dental work has not been considered in this study.

In order to consider inter-individual variation in mechanical exposure while performing identical tasks, the same dentists were studied in both 2003 and 2009. This allowed the use of paired tests. However, we have no detailed information about the specific treatments carried out during the observations. This may potentially hide differences in waste between 2003 and 2009.

\subsubsection{Operationalisation of the concept of rationalisation}

Rationalisation is defined as "the methods of technique and organisation designed to secure the minimum of waste of either effort or material" (World Economic Conference in Geneva, 1927 cited in Westgaard and Winkel (2011)). The analysis system used in the present study was developed for industrial use, and work tasks were classified according to an engineering and Lean Production approach (Liker 2004). During recent years, the concept of Lean Production has to an increasing extent been adopted by the service sector, including healthcare (e.g. Keyte and Locher 2004). The assessment of waste, as performed in the present study, implies that all activities which can be completed without the dentist having to 
move away from the patient are considered as VAW (cf. Engström and Medbo 1997). This approach may be too rough an operationalisation in healthcare, where the aim is to provide service to a patient. It has for example been suggested by Grönroos and Ojasalo (2004) that contributions from the patient should also be considered.

\subsection{General discussion}

\subsubsection{Duration of VAW and non-VAW}

The proportion of VAW was $57 \%$ in 2003 and $45 \%$ in 2009. Compared with studies using the same system for task analysis, Kazmierczak et al. (2005) assessed VAW to about 30\% in traditional car disassembly. Bao et al. (1996) and Neumann et al. (2006) recorded about 70\% VAW during industrialised sewing machine and motor assembly. Studies of the Finnish Public Dental Service and the Dental Service in the UK concluded that work organisation efficiency must be enhanced in order to achieve an overall minimisation of costs (Widstrom et al. 2004, Cottingham and Toy 2009). Thus, in the present study an increase in the proportion of VAW during follow-up was expected. A Swedish Government Official Report (SOU 2002) and Abelsen and Olsen (2008) emphasise that dental care teams need to be more efficient in order to meet increased demands for dental care. Allocation of work tasks to dental hygienists and dental assistants is part of this rationalisation. More time may therefore have been made available for dentists to carry out other tasks, but seemingly not for more VAW as defined in this study. At the investigated job level, i.e. the dentist level, the rationalisation seems not to have been successful in terms of waste reduction. However, in a parallel study of the same organisation an increase in productivity was found at the overall dental system level (Rolander et al. Submitted). This may be due to rationalisation effects at other professional levels of the investigated organisation, e.g. dental nurses, administrators etc. This emphasises 
the importance of including all occupational groups of a production system in the evaluation of changes in system sustainability during a period of rationalisation.

\subsubsection{Mechanical exposures during VAW and non-VAW tasks}

Changes in mechanical exposures during "patient treatment" (VAW) indicate more constrained head postures in 2009 compared with 2003. A forward head inclination of more than $15^{\circ}-20^{\circ}$ during "an extended period", may increase the risk of developing neck pain (Ohlsson et al. 1994, Ohlsson et al. 1995, Bernard 1997, Ariens et al. 2001). However, the increase in forward flexion of the head from $40^{\circ}$ to $46^{\circ}$ may be marginal in terms of increased risk. Using virtual reality simulation, Suebnukarn et al. (2009) showed that experienced dentists (aged 35-45 years) had a more dynamic force pattern in dental hand tool operations and faster task completion during dental crown preparation compared with dentist students (aged 20-23 years). This may be explained by a higher level of "motor learning", implying faster performance among the more experienced dentists. Our studies showed the opposite effect: i.e. a decreased range in movement velocities of the dominant arm during "patient treatment". Our group of dentists was 15 years older at follow-up compared with the experienced dentists above; the investigated follow-up period was only six years; and the measurements were performed during real work. In our study, the decreased range in movement velocities of the dominant arm during "patient treatment" may be due to a combination of an age effect and an effect of the implemented rationalisations. Further studies are needed to clarify this.

During "X-ray handling" (non-VAW), median elevation of the non-dominant upper arm was reduced from $35^{\circ}$ in 2003 to $23^{\circ}$ in 2009 . Upper arm elevation more than $30^{\circ}$ has been shown to obstruct blood flow to the supraspinatus muscle (Jarvholm et al. 1988). Thus, the present change in arm elevation between 2003 and 2009 may imply a significant risk 
reduction. However, for the right upper arm we found reduced movement velocities, indicating a more constrained posture for the dominant arm. This is probably due to the introduction of computerised routines during the follow-up period.

During "administration" (non-VAW), decreased movement velocities and narrower velocity ranges also indicate a more constrained working posture, possibly due to more intensive use of VDU. Similar results were found by Arvidsson et al. (2006) when evaluating physical workload of air traffic controllers following the computerisation of air traffic control systems.

In contrast to "X-ray handling" and "administration", "handling of parts and materials" (non-VAW) was more dynamic in 2009 compared with 2003, estimated as increased median head movement velocity and wider range of velocities for both arms. This change towards more dynamic working conditions may imply less hazardous mechanical exposures (Madeleine 2010).

The duration of individual work tasks is short and thus the risk implications with regard to WMSDs may be small. When pooling all separate non-VAW tasks, a better risk estimation due to mechanical exposures may be provided. Compared with pooled VAW, pooled nonVAW shows more upright postures for the head and back, as well as a wider range of movements for both upper arms. Thus, non-VAW seems to imply a lower risk of developing WMSD. This is in accordance with previous studies comparing mechanical exposures in VAW and non-VAW (Kazmierczak 2005, Ostensvik et al. 2008, Jonker et al. 2011).

\subsubsection{Mechanical exposure at job level}

The arm and head velocities ( $50^{\text {th }}$ percentiles) in the present study are low compared with industrial assembly work (Christmansson et al. 2002, Balogh et al. 2006). The low velocities reflect constrained postures that are typical of dental work, and our results thus seem to have good face validity. According to Hansson et al (2010), a dentist's work may be classified as 
"repetitive non-industrial work" when compared with previously investigated occupational groups using the same methods and procedures. This repetitive work seems to imply an elevated risk of WMSD in comparison with jobs involving varied mobile work, such as nursing and home service (Nordander et al. 2009).

Since the mechanical exposure level in the present study did not change from 2003 to 2009 , the risk level with regard to WMSD still seems to be high compared with occupational groups whose work is more varied (Bernard 1997, N.R.C. 2001, da Costa and Vieira 2010).

\subsubsection{Conclusion}

A set of organisational and technical changes was introduced in a public dental care system in Sweden to improve performance. Based on previous investigations of relations between rationalisation and exposures (Westgaard and Winkel 2011), it was hypothesised that this would lead to an increased risk of developing WMSD for dentists. However, this could not be shown at the dentist level of the dental system.

A parallel study of the same organisations demonstrated an increase in their productivity (Rolander et al. Submitted). This may be due to rationalisation effects at other levels of dentistry in the investigated organisations, e.g. among other occupational groups. Thus, all occupational groups in a production system need to be investigated to ensure a sustainable production system. 


\section{References}

Abelsen, B. \& Olsen, J.A., 2008. Task division between dentists and dental hygienists in Norway. Community Dent Oral Epidemiol, 36 (6), 558-66 .

Akesson, I., Balogh, I. \& Hansson, G.A., 2012. Physical workload in neck, shoulders and wrists/hands in dental hygienists during a work-day. Appl Ergon, 43 (4), 803-11.

Akesson, I., Johnsson, B., Rylander, L., Moritz, U. \& Skerfving, S., 1999. Musculoskeletal disorders among female dental personnel--clinical examination and a 5-year follow-up study of symptoms. Int Arch Occup Environ Health, 72 (6), 395-403.

Ariens, G.A., Bongers, P.M., Douwes, M., Miedema, M.C., Hoogendoorn, W.E., Van Der Wal, G., Bouter, L.M. \& Van Mechelen, W., 2001. Are neck flexion, neck rotation, and sitting at work risk factors for neck pain? Results of a prospective cohort study. Occup Environ Med, 58 (3), 200-7.

Arvidsson, I., Hansson, G.-Å., Mathiassen, S.E. \& Skerfing, S., 2006. Changes in physical workload with implemantion of mouse-based information technology in air traffic control. International Journal of Industrial Ergonomics, 36, 613-622.

Balogh, I., Hansson, G.-Å., Ohlsson, K., Stromberg, U. \& Skerfving, S., 1999. Interindividual variation of physical load in a work task. Scand J Work Environ Health, 25 (1), 57-66.

Balogh, I., Ohlsson, K., Hansson, G.-Å., Engström, T. \& Skerfving, S., 2006. Increasing the degree of automation in a production system: Consequences for the physical workload. International Journal of Industrial Ergonomics, 36, 353-365.

Bao, S., Mathiassen, S.E. \& Winkel, J., 1996. Ergonomic effects of a management-based rationalization in assembly work - a case study. Appl Ergon, 27 (2), 89-99..

Bejerot, E., Soderfeldt, B., Aronsson, G., Harenstam, A. \& Soderfeldt, M., 1999. Perceived control systems, work conditions, and efficiency among swedish dentists: Interaction between two sides of human resource management. Acta Odontol Scand, 57 (1), 4654.

Bernard, B.P., 1997. Musculoskeletal disorders and workplace factors: A critical review of epidemiologic evidence for work-related musculoskeletal disorders of the neck, upper extremity, and lower back. In Bernard, B.P. ed. Cincinnati: National Institute for Occupational Safety and Health (NIOSH), US Department of Health and Human Services, 97-141.

Bjorkman, T., 1996. The rationalisation movement in perspective and some ergonomic implications. Appl Ergon, 27 (2), 111-7.

Christmansson, M., Medbo, L., Hansson, G.-Å., Ohlsson, K., Unge Byström, J., Möller, T. \& Forsman, M., 2002. A case study of principally new way of materials kitting - an evaluation of time consumption and physical workload. Int. J. Ind, Ergon, 30, 49-65.

Cottingham, J. \& Toy, A., 2009. The industrialisation of the dental profession. Br Dent J, 206 (7), 347-50.

Da Costa, B.R. \& Vieira, E.R., 2010. Risk factors for work-related musculoskeletal disorders: A systematic review of recent longitudinal studies. Am J Ind Med, 53 (3), 285-323.

Dong, H., Loomer, P., Barr, A., Laroche, C., Young, E. \& Rempel, D., 2007. The effect of tool handle shape on hand muscle load and pinch force in a simulated dental scaling task. Appl Ergon, 38 (5), 525-31.

Engström, T. \& Medbo, P., 1997. Data collection and analysis of manual work using video recording and personal computer techniques. . International Journal of Industrial Ergonomics, 19, 291-298.

Finsen, L., Christensen, H. \& Bakke, M., 1998. Musculoskeletal disorders among dentists and variation in dental work. Appl Ergon, 29 (2), 119-25. 
Forsman, M., Hansson, G.A., Medbo, L., Asterland, P. \& Engstrom, T., 2002. A method for evaluation of manual work using synchronised video recordings and physiological measurements. Appl Ergon, 33 (6), 533-40.

Grönroos, C. \& Ojasalo, P., 2004. Service productivity - towards an conceptualization of the transfornation of economic results in service business. Journal of Business Research, $57,414-423$.

Hansson, G., Å., Balogh, I., Ohlsson, K., Granqvist, L., Nordander, C., Arvidsson, I., Åkesson, I., Unge, J., Rittner, R., Strömberg, U. \& Skerfing, S., 2010. Physical workload in various types of work: Part 2. Neck, shouder and upper arm. International Journal of Industrial Ergonomics, 40 (3), 267-281.

Hansson, G.A., Arvidsson, I., Ohlsson, K., Nordander, C., Mathiassen, S.E., Skerfving, S. \& Balogh, I., 2006. Precision of measurements of physical workload during standardised manual handling. Part ii: Inclinometry of head, upper back, neck and upper arms. $J$ Electromyogr Kinesiol, 16 (2), 125-36.

Hansson, G.A., Asterland, P., Holmer, N.G. \& Skerfving, S., 2001. Validity and reliability of triaxial accelerometers for inclinometry in posture analysis. Med Biol Eng Comput, 39 (4), 405-13 Available from: http://www.ncbi.nlm.nih.gov/pubmed/11523728.

Hayes, M., Cockrell, D. \& Smith, D.R., 2009. A systematic review of musculoskeletal disorders among dental professionals. Int J Dent Hyg, 7 (3), 159-65.

Jarvholm, U., Palmerud, G., Styf, J., Herberts, P. \& Kadefors, R., 1988. Intramuscular pressure in the supraspinatus muscle. J Orthop Res, 6 (2), 230-8.

Jonker, D., Rolander, B., Balogh, I., Sandsjo, L., Ekberg, K. \& Winkel, J., 2011. Mechanical exposure among general practice dentists in Sweden and possible implications of rationalisation. Ergonomics, 54 (10), 953-60.

Kazmierczak, K., 2005. Industrial development of car disassembly - ergonomics and system performance. Lund.

Kazmierczak, K., Mathiassen, S.E., Forsman, M. \& Winkel, J., 2005. An integrated analysis of ergonomics and time consumption in swedish 'craft-type' car disassembly. Appl Ergon, 36 (3), 263-73.

Kazmierczak, K., Mathiassen, S.E., Neumann, P. \& Winkel, J., 2006. Observer reliability of industrial activity analysis based on video recordings. International Journal of Industrial Ergonomics, 36, 275-282.

Keyte, B. \& Locher, D., 2004. The complete lean enterprise. Value stream mapping for administrative and office processes. New York. : Productivity Press.

Leggat, P.A., Kedjarune, U. \& Smith, D.R., 2007. Occupational health problems in modern dentistry: A review. Ind Health, 45 (5), 611-21.

Liker, J., K., 2004. The toyota way - 14 management principles from the world's greatest manufacturer. New York: McGraw-Hill.

Madeleine, P., 2010. On functional motor adaptations: From the quantification of motor strategies to the prevention of musculoskeletal disorders in the neck-shoulder region. Acta Physiol (Oxf), 199 Suppl 679, 1-46.

Mathiassen, S.E. \& Svendsen, S.W., 2009. Sytematic and random errors in postures percentiels assessed from limitid exposure samples. 17th world Congress on Ergonomics, IEA 2009. Beijing.

Munvädret, 2003:9. The Jönköping dental county council's public company newsletter. In Swedish.

National Research Council., 2001. Musculoskeletal disorders and the workplace: Low back and upper extremities. Washington, DC: National Academy Press.

Neumann, W.P., Winkel, J., Medbo, L., Magneberg, R. \& Mathiassen, S.E., 2006. Production system design elements influencing productivity and ergonomics - a case study of 
parallel and serial flow strategies. International Journal of Operations \& Production Management, 26, 904-923.

Nordander, C., Ohlsson, K., Akesson, I., Arvidsson, I., Balogh, I., Hansson, G.A., Stromberg, U., Rittner, R. \& Skerfving, S., 2009. Risk of musculoskeletal disorders among females and males in repetitive/constrained work. Ergonomics, 52 (10), 1226-39.

Ohlsson, K., Attewell, R.G., Johnsson, B., Ahlm, A. \& Skerfving, S., 1994. An assessment of neck and upper extremity disorders by questionnaire and clinical examination. Ergonomics, 37 (5), 891-7.

Ohlsson, K., Attewell, R.G., Palsson, B., Karlsson, B., Balogh, I., Johnsson, B., Ahlm, A. \& Skerfving, S., 1995. Repetitive industrial work and neck and upper limb disorders in females. Am J Ind Med, 27 (5), 731-47.

Ostensvik, T., Veiersted, K.B., Cuchet, E., Nilsen, P., Hanse, J.J., Carlzon, C. \& Winkel, J., 2008. A search for risk factors of upper extremity disorders among forest machine operators: A comparison between France and Norway. International Journal of Industrial Ergonomics, 38, 1017-1027.

Ratzon, N.Z., Yaros, T., Mizlik, A. \& Kanner, T., 2000. Musculoskeletal symptoms among dentists in relation to work posture. Work, 15 (3), 153-158.

Rolander, B., Jonker, D., Winkel, J., Sandsjo, L., Balogh, I., Svensson, E. \& Ekberg, K., Submitted. Working conditions, health and produtivity among dentists - a propective study during rationalization in public dental care.

Sou, 2002. Swedish national public investigations.

Suebnukarn, S., Phatthanasathiankul, N., Sombatweroje, S., Rhienmora, P. \& Haddawy, P., 2009. Process and outcome measures of expert/novice performance on a haptic virtual reality system. J Dent, 37 (9), 658-65.

Tornqvist, E.W., Hagberg, M., Hagman, M., Risberg, E.H. \& Toomingas, A., 2009. The influence of working conditions and individual factors on the incidence of neck and upper limb symptoms among professional computer users. Int Arch Occup Environ Health, 82 (6), 689-702.

Westgaard, R.H. \& Winkel, J., 2011. Occupational musculoskeletal and mental health: Significance of rationalization and opportunities to create sustainable production systems - a systematic review. Appl Ergon, 42 (2), 261-96.

Widstrom, E., Linna, M. \& Niskanen, T., 2004. Productive efficiency and its determinants in the finnish public dental service. Community Dent Oral Epidemiol, 32 (1), 31-40.

Winkel, J. \& Westgaard, R.H., 1996. A model for solving work related musculoskeletal problems in a profitable way. Appl Ergon, 27 (2), 71-7. 
Table 1. Description and classification of the investigated work tasks and the proportion of time spent on them in mean percent and CI 95\% [in brackets], based on 45 minutes of video registration of observed work activities in 2003 and $2009, \mathrm{n}=12$.

\begin{tabular}{|c|c|c|c|c|c|}
\hline Classification & Work tasks & Description & $\begin{array}{l}\text { Proportion of } \\
\text { time in } 2003\end{array}$ & $\begin{array}{l}\text { Proportion of } \\
\text { time in } 2009\end{array}$ & $\mathrm{p}=$ \\
\hline \multirow[t]{2}{*}{ VAW } & Patient treatment & $\begin{array}{l}\text { Principal activities during } \\
\text { patient dental treatment, e.g. } \\
\text { dental examination, dental } \\
\text { filling therapy, tooth } \\
\text { extraction, assessing X-ray } \\
\text { pictures and reading } \\
\text { patient's journal during } \\
\text { dental treatment, reaching } \\
\text { for tools and materials } \\
\text { during dental patient } \\
\text { treatment }\end{array}$ & $47.2[36.3-58.1]$ & $34.4[22.2-46.5]$ & 0.14 \\
\hline & Dental information & $\begin{array}{l}\text { Dentist's information about } \\
\text { treatment during the dental } \\
\text { treatment } \\
\text { Conversation about dental } \\
\text { treatment with patient or } \\
\text { relatives to the patient } \\
\text { during treatment }\end{array}$ & $10.1[5.8-14.4]$ & $10.4[5.2-15.7]$ & 0.64 \\
\hline \multirow[t]{4}{*}{ Non-VAW } & X-ray handling & $\begin{array}{l}\text { Taking X-ray pictures, } \\
\text { assessing and storing }\end{array}$ & $5.9[2.4-9.4]$ & $9.2[3.5-14.9]$ & 0.31 \\
\hline & Administration & $\begin{array}{l}\text { Writing/reading and } \\
\text { dictation to the patient file }\end{array}$ & $14.1[11.5-16.7]$ & $15.9[9.7-22.2]$ & 0.92 \\
\hline & $\begin{array}{l}\text { Handling of parts } \\
\text { and materials }\end{array}$ & $\begin{array}{l}\text { Adjusting patient and/or } \\
\text { operator chair, handling } \\
\text { tools and materials, hand } \\
\text { hygiene } \\
\text { Transfers of the dentist in } \\
\text { the dental practice } \\
\text { Walking to the next patient }\end{array}$ & $14.3[9.8-18.9]$ & $18.4[13.4-23.5]$ & 0.10 \\
\hline & Disturbances & $\begin{array}{l}\text { Short spontaneous breaks } \\
\text { during treatment lasting for } \\
\text { more than one second } \\
\text { Social communication with } \\
\text { patients or colleagues } \\
\text { Short spontaneous breaks } \\
\text { Waiting }\end{array}$ & 8.2 [1.8-14.6] & $11.7[6.3-17.0]$ & 0.14 \\
\hline Total VAW & & & $57.3[49.5-65.2]$ & $44.8[32.2-57.4]$ & 0.12 \\
\hline $\begin{array}{l}\text { Total non- } \\
\text { VAW }\end{array}$ & & & $42.6[34.7-50.4]$ & $55.2[42.6-67.8]$ & 0.10 \\
\hline
\end{tabular}


Table 2. Mean frequency $\left(\mathrm{h}^{-1}\right)$ of changes between work tasks and mean duration (s) of uninterrupted periods of VAW and non-VAW activities [min-max] in 2003 and 2009, $\mathrm{n}=12$.

\begin{tabular}{llll}
\hline & Year 2003 & Year 2009 & $\mathrm{p}=$ \\
\hline Frequency /hour & $54[20-106]$ & $41[15-72]$ & 0.12 \\
Duration of VAW & $91[40-172]$ & $85[46-182]$ & 0.62 \\
Duration of non-VAW & $65[23-161]$ & $106[25-234]$ & 0.09
\end{tabular}

Paired t-test for differences between years 2003 and 2009.

URL: http://mc.manuscriptcentral.com/terg E-mail: ergonomics@tandf.co.uk 
Table 3. Postures (deg) assessed for each of the investigated tasks and the job as a whole. Positive angles denote forward flexion for both head and back, $\mathrm{n}=12$.

Pooled and specific VAW and non-VAW tasks: Group means of $50^{\text {th }}$ percentile and of differences between $90^{\text {th }}$ and $10^{\text {th }}$ percentiles [CI $95 \%$ in brackets] for the head, back and upper arms, during the 45 minutes of video recording.

Job: Group means of $50^{\text {th }}$ percentile [CI $95 \%$ in brackets] for the head, back and upper arms, during the 45 minutes of video recording and four hours of dental work.



* Significance for paired t-test for differences between the same work activities in 2003 and 2009, $\mathrm{p}<0.05$.

1. Significance for paired $t$-test for differences between VAW and non-VAW in 2003, $\mathrm{p}<0.05$.

2. Significance for paired t-test for differences between VAW and non-VAW in 2009, $\mathrm{p}<0.05$.

a Paired t-test for differences between four hours of inclinometry registration and 45 minutes of video recordings, $p<0.05$. 
Table 4. Velocities (deg/s) assessed for each of the investigated tasks and the job as a whole, $\mathrm{n}=12$.

Pooled and specific VAW and non-VAW tasks: Group means of $50^{\text {th }}$ percentile and of differences between $90^{\text {th }}$ and $10^{\text {th }}$ percentiles $[\mathrm{CI}$ $95 \%$ in brackets] for the head, back and upper arms, during the 45 minutes of video recording.

Job: Group means of $50^{\text {th }}$ percentile [CI $95 \%$ in brackets] for the head, back and upper arms, during the 45 minutes of video recording and four hours of dental work .

$\begin{array}{cllll}\text { Head angle } & \text { Back angle } \\ \text { (sagittal plane) } & \text { (sagittal plane) } & \begin{array}{c}\text { Dominant upper } \\ \text { arm elevation }\end{array} & \begin{array}{l}\text { Non-dominant upper } \\ \text { arm elevation }\end{array}\end{array}$

\begin{tabular}{|c|c|c|c|c|c|c|c|c|c|c|c|c|}
\hline & 2003 & 2009 & $\mathrm{p}=$ & 2003 & 2009 & $\mathrm{p}=$ & 2003 & 2009 & $\mathrm{p}=$ & 2003 & 2009 & $\mathrm{p}=$ \\
\hline \multicolumn{13}{|l|}{$\begin{array}{l}\text { VAW } \\
\text { work tasks }\end{array}$} \\
\hline $\begin{array}{l}\text { Patient } \\
\text { treatment }\end{array}$ & & & & & & & & & & & & \\
\hline & $3.9[3.3-4.5]$ & $3.5[2.8-4.3]$ & 0.18 & $2.8[2.4-3.2]$ & $2.6[2.1-3.0]$ & 0.38 & $8.2[6.6-9.8]$ & $7.3[5.8-8.8]$ & 0.36 & $5.7[4.7-6.7]$ & $5.9[4.6-7.2]$ & 0.99 \\
\hline$m \operatorname{diff} 90^{\text {th }} 10^{\text {th }}$ & 25 [22-29] & $20[16-24]^{*}$ & 0.01 & 17 [15-19] & $14[12-16]$ & 0.06 & $45[38-53]$ & $34[30-39]^{*}$ & 0.01 & $30[26-36]$ & 29 [24-34] & 0.57 \\
\hline $\begin{array}{l}\text { Dental } \\
\text { information }\end{array}$ & & & & & & & & & & & & \\
\hline$m 50^{\text {th }}$ & $6.8[4.5-9.1]$ & $8.3[5.9-11]$ & 0.28 & $4.8[3.1-6.4]$ & $5.3[3.9-6.7]$ & 0.64 & 11 [7.5-15] & $12[9.2-16]$ & 0.73 & 9.8 [6.3-13] & 11 [8.4-14] & 0.61 \\
\hline$m$ diff $90^{\text {th }} 10^{\text {th }}$ & 41 [28-53] & $44[30-59]$ & 0.58 & 26 [19-34] & 27 [21-34] & 0.89 & $61[45-76]$ & 59 [48-70] & 0.87 & 49 [35-63] & $51[40-63]$ & 0.80 \\
\hline
\end{tabular}

Non-VAW

work tasks

X-ray

handling

$m 50^{\text {th }}$

$6.8[4.6-9.1] \quad 5.6[4.0-7.3] \quad 0.28$

$m$ diff $90^{\text {th }} 10^{\text {th }} \quad 39[30-49] \quad 36[26-46] \quad 0.41$

$\begin{array}{llllll}5.2[3.2-7.3] & 3.7[2.3-5.0] & 0.22 & 15[10-21] & 9[4.7-13] & 0.08\end{array}$

$13[6.7-19] \quad 8[4.5-12] \quad 0.23$

Administration

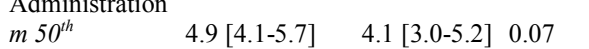

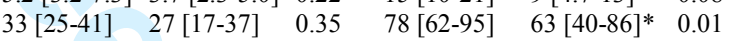

$70[52-88]-60[40-82]$

0.48

$m$ diff $90^{\text {th }} 10^{\text {th }} \quad 34[28-40]$

$4[17-31]^{*} 0.01$

$3.4[2.7-4.1] \quad 2.6[1.8-3.5] * 0.03 \quad 9.3[7.3-11] \quad 6.6[4.3-9.0] * 0.01$

$7.4[5.5-9.3] \quad 5.7[3.5-8.0]^{*} \quad 0.01$ $3[19-28] \quad 33[26-39]^{*} 0.008 \quad 58[47-69] \quad 32[26-39]^{*} 0.001$

$46[37-55] \quad 29[21-36]^{*} \quad 0.001$

Handling parts

and materials

$m 50^{\text {th }}$

$m$ diff $90^{\text {th }} 10^{\text {th }}$

$6.4[3.6-9.2] \quad 9.0[7.7-10] \quad 0.12$

$19[11-27] \quad 27[24-31] \quad 0.09$

$16[8.8-23] \quad 25[22-29]^{*} \quad 0.03$

$51[37-64] \quad 58[50-67] \quad 0.12 \quad 36[25-46] \quad 47[41-53]^{*} \quad 0.06 \quad 84[64-104] \quad 107[95-120] * 0.05$

$70[53-88] \quad 99[86-112]^{*} \quad 0.02$

Disturbances

$\begin{array}{llll}m 50^{\text {th }} & 8.9[5.0-13] & 9.7[6.7-13] & 0.72\end{array}$

$\begin{array}{lllllll}6.2[3.1-9.2] & 6.5[3.8-9.3] & 0.84 & 18[7.5-27] & 16[7.7-24] & 0.75\end{array}$

$15[7.3-23] \quad 15[8.0-22]$

$70[45-95] \quad 73[52-95]$

0.99

$m$ diff $90^{\text {th }} 10^{\text {th }} \quad 47[32-63]$

$39[27-51] \quad 0.40$

$35[21-49] \quad 14[10-18] \quad 0.55$

$80[51-109] \quad 78[54-103] \quad 0.90$

Pooled VAW

$m 50^{\text {th }}$

$4.3[3.1-5.5]$

$m$ diff $90^{\text {th }} 10^{\text {th }}$

$4.3[3.1-5.5]$
$28[20-35]$

0.71

$2.9[2.5-3.4] \quad 3.0[2.3-3.7] \quad 0.76$

$\begin{array}{lll}8.4[6.8-10] & 8.2[6.6-9.8] & 0.84\end{array}$

$6.0[5.0-7.1] \quad 6.8[5.3-8.3]$

$34[29-39] \quad 36[29-43]$

0.36

Pooled non-

VAW

$m 50^{\text {th }} \quad 6.6[5.1-8.1]^{1}$

$7.1[5.6-8.5]^{2} \quad 0.39$

$18[24-40] 18[14-22]$

$\begin{array}{lllll}.83 & 48[41-55] & 42[35-49] & 0.19\end{array}$

$11[8.1-14]^{1} \quad 12[8.4-15]^{1}$

$66[52-79]^{1} \quad 72[58-86]^{2}$

0.70

$m$ diff $90^{\text {th }} 10^{\text {th }} 43[35-52]$

$47[39-55]^{2} \quad 0$.

$\begin{array}{ll}32[25-39]^{1} & 34[28-40]^{2}\end{array}$

$\begin{array}{llll}0.83 & 13[10-17] & 13[9.5-16]^{1} & 0.79\end{array}$

Job exposure

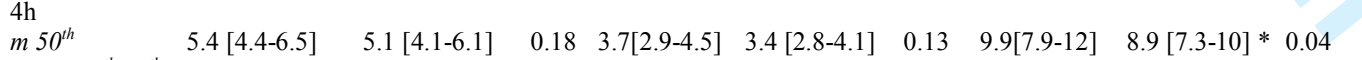

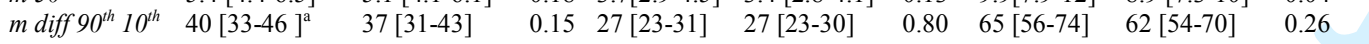

$8.0[6.1-9.9] \quad 7.6[6.0-9.2] \quad 0.23$

$45 \mathrm{~min}$

$m 50^{t h}$

$m$ diff $90^{\text {th }} 10^{\text {th }}$

$5.1[4.1-6.1] \quad 5.5[4.2-6.8]$

$\begin{array}{lllllll}0.29 & 3.5[2.8-4.2] & 3.7[2.9-4.6] & 0.33 & 9.7[7.7-12] & 9.9[7.8-12] & 0.70\end{array}$

$7.8[5.9-9.3] \quad 8.5[6.5-11]$

0.09

* Significance for paired t-test for differences between same work activities in 2003 and 2009, $\mathrm{p}<0.05$.

1. Significance for paired t-test for differences between VAW and non-VAW in 2003, $p<0.05$.

2. Significance for paired t-test for differences between VAW and non-VAW in 2009, $\mathrm{p}<0.05$.

a Paired $\mathrm{t}$-test for differences between $4 \mathrm{~h}$ inclinometry registration and 45 minutes of video recordings, $\mathrm{p}<0.05$. 